\title{
Erratum to: Understanding ESL Student Teachers' Learning of Classroom Practices in the Practicum: A Case Study in Hong Kong
}

\author{
Zhengdong Gan $^{1} \cdot$ Jackie Fung King Lee ${ }^{2}$
}

Published online: 26 February 2016

(C) De La Salle University 2016

\section{Erratum to: Asia-Pacific Edu Res \\ DOI 10.1007/s40299-015-0258-x}

In the original publication of the article, the second author name on the first page and its initials at the top of each page had been published incorrectly. However, the correct author name and its initial should be: Jackie Fung King Lee and J. F. K. Lee

The online version of the original article can be found under doi: 10.1007/s40299-015-0258-x.

Zhengdong Gan

ZhengdongGan@umac.mo

1 Faculty of Education, University of Macau, Macau, China

2 Department of Linguistics and Modern Language Studies, The Hong Kong Institute of Education, Tai Po, Hong Kong 